\title{
Recommendations for Surgery During the COVID-19 Pandemic
}

\author{
Jitendra Kumar ${ }^{1}$ (ID) Rajni Raina $^{2}$ (I)
}

Received: 17 May 2020 / Accepted: 5 June 2020 / Published online: 11 June 2020

(C) Association of Surgeons of India 2020

Dear Editor in Chief,

Indian Journal of Surgery

An article like "Recommendations for Surgery During the Novel Coronavirus (COVID-19) Epidemic" by Liu et al. is need of an hour [1]. That is the reason why we read this very keenly. This is a very nice attempt by an author to address our current problems due to COVID-19 pandemic. We read this article very carefully and felt like highlighting certain issues in larger interest of patient care.

Scientifically, recommendations are derived from best of the available evidence collected from the research. Clinicians decide to follow the recommendations solely on the basis of strength and quality of evidence on which these are based [2]. Since the outset of COVID-19 pandemic, there are deluge of recommendations and guidelines starts pouring all over. All of these recommendations are based on either anecdotal case reports, case series of insignificant numbers or expert opinions [3]. In the beginning, probably it was a desperate attempt to disseminate the available information, to manage this unprecedented global health crisis created out of COVID-19 pandemic.

"Recommendations for Surgery During the Novel Coronavirus (COVID19) Epidemic" by Liu et al. [Indian J Surgery 82(2), 124 - 128 (April 2020)]

Jitendra Kumar

jkumar33@ymail.com

1 Department of Surgery, Dr B. S. A. Medical College \& Hospital, Sector - 6, Rohini, New Delhi 110085, India

2 Department of Anaesthesia, Dr B.S.A. Medical College \& Hospital, Rohini, New Delhi 110085, India
So far, all recommendations for management of surgical patients during COVID-19 pandemic, issued by different professional bodies, are revolving around three issues - triagebased on possible harm to the patients in case if surgery is delayed, availability of resources in the hospital and countering the risk potential of COVID-19 [3-5]. Most of the recommendations have advised postponement of non-essential elective surgery except in certain countries for, e.g. South Korea and Singapore, who have continued their elective surgery throughout the COVID-19 outbreak [3-5].

SARS CoV-2 virus is novel pathogen, and many of its characters and behaviours are yet to be explored, and it has got variable impact over different geographical location of the world. Because of these reasons, all recommendations issued so far in respect of COVID-19 pandemic are interim in nature, and most of them are being updated on regular basis [3-5]. This article too is based on interim recommendations, issued by different authorities and organisations like C.D.C. USA, A.C.S. USA, N.C.P. RCS. Ireland, N.H. C. of China and W.H.O. [1].

This is a very good article in terms of the safety precaution measures for health care workers and the patients, but certain area of recommendations mentioned in the article is a matter of debate. In case of emergency surgery, authors have advised COVID-19 testing only for the suspected patients. Also, they have advised adoption of only general protection measure by surgeons and anaesthetists for low-risk patients during the surgery, and accordingly, such patients can be shifted to original ward. Authors quoted the ICMR guidelines (issued for testing strategy of general population of India) for testing of only high-risk patients before elective surgery, but this needs to be reviewed. As COVID-19 comprises of high majority of asymptomatic patients and in presence of community spread, chance of getting the suspicious history will be negligible, so it is always recommended to test every patient before elective surgery [6]. 
A.S.I. must come forward with proposal to constitute surgical review committee to formulate some structured framework suitable for our country to manage surgical patients efficiently during and after this global emergency.

Acknowledgements We acknowledge all those patients whether of COVID-19 or non-COVID-19, whose sufferings inspired us to write this article in the hope of some solution and betterment from their current plight.

Authors' Contribution Original idea of this article and conceptualisation work is of Dr. Jitendra Kumar (corresponding author) while literature search, data analysis, drafting and revision work was equally done by Dr. Rajni Raina.

We also declare as follows:

- That the manuscript is not under consideration elsewhere.

- That the work is original.

- That all authors have agreed to submission to The Indian Journal of Surgery.

\section{Compliance with Ethical Standards}

Conflict of Interest The authors declare that they have no conflict of interest.

Ethical Approval This article does not contain any studies with human participants or animals performed by any of the authors.

Informed Consent Informed consent was not applicable in this case.

\section{References}

1. Liu Z, Zhang Y, Wang X, Zhang D, Diao D, Chandramohan K, Booth CM (2020) Recommendations for surgery during the novel coronavirus (COVID-19) epidemic. Indian J Surg 82(2):124-128. https://doi.org/10.1007/s12262-020-02173-3

2. Michie S, Berentson-Shaw J, Pilling S et al (2007) Turning evidence into recommendations: protocol of a study guideline development groups. Implement Sci 2:29. Published 2007 Sep 5. https://doi.org/ 10.1186/1748-5908-2-29

3. Søreide K, Hallet J, Matthews JB, Schnitzbauer AA, Line PD, Lai PBS et al (2020) Immediate and long-term impact of the COVID-19 pandemic on delivery of surgical services. Br J Surg. https://doi.org/ 10.1002/bjs. 11670

4. Global guidance for surgical care during the COVID-19 pandemic. Br J Surg. 2020. doi: https://doi.org/10.1002/bjs.11646.

5. American College of Surgeons. COVID-19: guidance for triage of non-emergent surgical procedures. https://www.facs.org/about-acs/ covid-19/information-for-surgeons/triage [Accessed on 16 May 2020]

6. Al-Muharraqi MA (2020) Testing recommendation for COVID-19 (SARS-CoV-2) in patients planned for surgery- continuing the service and 'suppressing' the pandemic. Br J Oral Maxillofac Surg 58: 503-505. https://doi.org/10.1016/j.bjoms.2020.04.014

Publisher's Note Springer Nature remains neutral with regard to jurisdictional claims in published maps and institutional affiliations. 